\title{
Delphic oracles: ambiguity, institutions, and multiple streams
}

\author{
Nikolaos Zahariadis ${ }^{1}$
}

Published online: 29 January 2016

(C) Springer Science+Business Media New York 2016

\begin{abstract}
The aim of the special issue is to explore a neglected aspect of the multiple streams approach (MSA): the impact of institutions in amending (or not) the framework's logic and hypotheses. The articles address this issue drawing on evidence from the Czech Republic, Germany, Norway, and the European Union. After discussing the origins and elements of multiple streams, I lay out the challenges posed by including institutions in MSA and introduce some of the ways the authors have attempted to overcome them. I argue the inclusion of institutions challenges and enriches but does not seriously amend the logic of MSA.
\end{abstract}

Keywords Multiple streams · Institutions · Ambiguity · Garbage cans

The aim of the special issue is to explore a neglected aspect of the multiple streams approach (MSA): the impact of institutions in amending (or not) the framework's logic and hypotheses. Institutions are defined as systems of formally or informally embedded social rules that may constrain or enable policy-making (March and Olsen 1989). One of MSA's major criticisms is the framework's inability to explicitly incorporate institutional dynamics into the logic of policy-making and to derive testable hypotheses (Schlager 2007). The authors address this issue drawing on evidence from four comparative settings: the Czech Republic, Germany, Norway, and the European Union (EU).

In this introduction, I first discuss the origins and elements of MSA. I then lay out the challenges posed by including institutions in MSA and finally briefly introduce some of the ways the authors have attempted to overcome them. I argue inclusion of the institutions enriches and complicates but does not seriously amend the logic of MSA.

Nikolaos Zahariadis

nzaharia@uab.edu

1 Department of International Studies, Rhodes College, 2000 North Parkway, Memphis, TN 38112, USA 


\section{Origins and elements of multiple streams}

In classical times Pythia, the priestess of Apollo Loxias (roughly translated as Apollo the ambiguous interpreter), delivered prophecies by uttering incomprehensible words that priests needed to interpret to anxious pilgrims who sought the god's favor and benevolence. The priests of course understood the importance of ambiguity in human affairs, especially in matters of state. Many pilgrims to Delphi were kings, generals, and public officials who based decisions of war and peace on the god's wishes. Clear prophecies would have been better than the incomprehensible oracles handed down by the priestess, but that was neither profitable nor preferable. Ambiguity served the useful role of enriching the priests, while it provided meaning and divine inspiration to the pilgrims. It enabled priests to always be right because they took advantage of what we might call today selective attention and interpretation.

At one level, Delphic oracles were about instrumentality and rational choice. Priests took advantage of "gullible" pilgrims to deliver prophecies in return for riches and prestige. They made strategic calculations about what to say, to whom, and for what purpose. They sought as much information as possible about the person in front of them in order to deliver the oracle with the most net benefits for the priests. They also understood full well that speaking truth to power is a dangerous endeavor; so the oracles were carefully crafted to please and appease. Otherwise, pilgrims would not return or worse, they might turn against the priests in a fit of rage.

At another level, Delphic oracles were a game of useful deception. The prophecies were crafted in a way that took on many meanings so that pilgrims heard what they wanted to hear. Cleansing and celebratory rituals were carefully constructed to add legitimacy to the whole affair so that meaning and divine inspiration were linked seamlessly to human reason. Perhaps pilgrims, and certainly the priests, understood the true nature of the Delphic process, but no one seemed to mind. Adding a little pomp and circumstance to the process of divine revelation and preference construction provided food for the rational soul.

The MSA conceptualizes public policy somewhat like the Delphic oracle, a ritualistic process with ambiguous messages that generate conflicting interpretations (Zahariadis 2014). Ambiguity is defined as the presence of multiple, conflicting, and irreconcilable interpretations public events, situations, and processes. It is operationalized by way of three indicators: problematic preferences, opaque technology, and fluid participation. Actors in policy-making are often faced with decisions without having formulated a priori clear and consistent preferences. They do not understand well how the process works, especially when it involves multiple agencies across administrative or national jurisdictions. Finally, participation rates vary across venues making presence in decision-making arenas at least as equally important as position in institutional hierarchies (March and Romelaer 1976).

MSA was developed as an explanatory framework to be used under conditions of ambiguity that other frameworks dismiss as an aberration. It does not reject but rather supplements rational choice. It derives inspiration from Cohen et al.'s (1972) garbage can model of organizational choice and was first used by Kingdon (1984) to explain agenda setting at the national level in the USA.

Standard decision-making theory views organizational decision-making as intentional, consequential action, whereby actors have consistent, exogenous preferences, time to look for and evaluate alternatives, and clear and stable decision rules. However, these conditions do not hold in many cases calling for alternative conceptualizations of the process that more closely approximate what people actually experience (March 1991). Cohen et al. 
(1972) developed a vision which saw organizational processes as occasions for conflicting demands on the attention of participants operating in loosely coupled and partially overlapping environments. The authors conceptualize a garbage can process of choice consisting of four relatively independent elements or streams: choice opportunities, problems, solutions, and decision-makers. Interactions among the four elements follow a temporal logic, that is, the varying speed by which elements arrive and depart from the choice arena. At a given choice, opportunity problems and solutions attach to each other not because of their inherent link as means-ends chains but because of their temporal proximity. At its limit, any solution can address (though not necessarily solve) any problem because they are contemporaries. These problem-solution packages are in turn tracked by decision-makers who move in and out of decisions depending on competing demands on their attention. The end result is a capricious process that is bounded by organizational structure and the energy (available resources) a decision-maker brings to a given choice.

Kingdon (1984) adapted this conceptualization to understand the problem of agenda setting. How does an idea's time come? How do issues become problems in the first place? Adapting the garbage can logic to public policy, Kingdon developed a model to explain agenda setting at the federal level in the USA. He conceptualized three streams-problems, policies, and politics-incorporated actors in all three streams, added the importance of policy entrepreneurs as facilitators of choice, and revisited the concept of choice opportunities by linking them to either the problem or politics streams. Problems are perceived gaps or deviations from a desired social state of affairs, such as inflation, pollution, or inaccessible health care. Policies are ideas proposed, advocated, and debated in narrow policy communities. Politics includes macro-level actors, such as political parties and the national mood. The policy process is loosely coupled in the sense that the streams are independent: Each obeys its own dynamics and rules. For example, while many ideas may float in the policy stream, relatively few gain wide acceptance among policy community professionals. Focusing events tend to direct attention to some problems and away from others. Streams are weakly linked but not nested; they may interact, but they do not covary (Orton and Weick 1990). For example, policies, such as privatization, developed to address one problem, such as lack of public funds, may end up addressing another, such as the creation of an entrepreneurial culture (Zahariadis 1995).

Issues are more likely to rise and fall on the agenda when all three streams are coupled or joined together by skilled policy entrepreneurs during open policy windows. Windows are defined as occasions for policy change, and they open when major changes happen in either the problem or politics streams. For example, the events of $9 / 11$ opened a policy window for a host of policies (Birkland 2004). National elections also open windows in the politics stream by providing the opportunity for a new administration to come to power and highlight a different set of issues and priorities. The logic of MSA has recently been expanded to cover policy formation (Zahariadis 2003) and implementation (Ridde 2009) across issues and levels of governance. However, despite numerous comparative applications (Jones et al. 2016), MSA theorizing has been somewhat devoid of institutions.

\section{Institutions, ambiguity, and public policy}

The institutional complexion of a policy system greatly affects policy performance, that is, the efficiency of the system and the effectiveness of problems and solutions that may be considered. Not all policy-makers may attend to all problems at the same time. Not all 
solutions see the light of day. Institutions structure this process serving two important functions: They both constrain and enable policy choice (March and Olsen 1989). Here I summarize the relationship between institutions, ambiguity, and public policy, and in the next section, I address implications for MSA. This summary has two benefits: to reduce the vast literature on institutions (e.g., Peters 2012) to only two relevant strands (as constraints and facilitators) and to help situate the MSA within the uneasy tension between those strands.

Choices are often conceived as the pursuit of consistent preferences based on a portfolio of options with estimates of anticipated consequences in constraining institutional contexts. As stable sets of informal and formal rules that structure patterned interactions of groups of individuals, institutions imbue predictability and decrease uncertainty (North 1990). But they also bias priorities, prejudice solutions, and distort the length and contestability of the process. A rougher institutional morphology (i.e., more numerous and more autonomous institutions) produces friction, elongating the policy process and increasing political conflict (Schattschneider 1960; Jones and Baumgartner 2005). For example, when a policy has to pass through many institutions before it is adopted, the rate of adoption is likely to slow down to fit with institutional calendars. Moreover, because different groups have access to different institutions, policies will face more resistance and pressure for compromise, as they need to appeal to groups with different agendas and preferences. Choice is reduced to selection among a limited number of issues and options based on what is institutionally permissible or viable. The US legislative system of multiple institutions and access points stands in sharp contrast to the British system of unicameral, majoritarian democracy.

Apart from constraining choice, institutions also enable it by generating meaning (Peters 2012, 19). Perceptual cues and frames that evoke and shape meaning often trigger action in particular situations (Weick 1995, 49-55). In this sense, institutionalized frames and institution-derived identities also edit and prime attention and meaning through feedback processes and contextual validation. Weber and Glynn $(2006,1646)$ go as far as to suggest that "institutions, in the form of institutionalized combinations of identities, frames and performance expectations, may in fact 'steer' action in a direct, taken-forgranted way." For example, national legislative procedures and institutions shape individual beliefs about who people are and to which communities they belong. This is done via three mechanisms: They can be nested and consensual (e.g., Germany and Spain), cross-cutting and contested (e.g., France), or separate and contradictory (e.g., the UK) (Risse 2010,10). Identities in turn help explain popular support under certain conditions for greater cross-national economic cooperation, restrictive immigration, and the like. To take another example, members of the European Parliament choose from a menu of options depending on the degree of overlapping partisan and European identities. Institutional rules facilitate the mix, which in turn biases policy in different directions.

Ambiguity poses two important challenges for institutions and the study of public policy. First, because conceptions of institutions differ along the axes of stability and political conflict, they have different consequences for policy formation. The concept of ambiguity suggests institutions can take on two or more meanings depending on situational context (Hajer 2003). Such multiplicity of meanings provides scope for creative interpretation both constraining and facilitating choice. Ambiguity empowers actors to continually reinterpret institutional opportunities and constraints, thereby generating instability and political tension. Because institutions remain an imperfect guide for action, actors may discover new interpretations of an institution over time, creating a state of flux in the form of constantly renegotiating institutional compromises. This is particularly true for losers 
who have incentives to seek new interpretations to curb distributional disadvantages (Mahoney and Thelen 2010). In this sense, boundaries and rules of behavior become contextual and politically contested. Policy change is therefore neither gradual nor punctuated but rather it depends on the degree of ambiguity and temporal context. Opportunities connect actors, strategies, and policy content. In a policy framework such as MSA, which assumes the presence of generous ambiguity, institutionalized rules and expectations represent contingencies that need to be specified in particular contexts. The logic in turn requires careful theorizing of the duality of institutions and ambiguity to specify the mechanisms and conditions that promote or inhibit policy change.

Second, ambiguity helps shape the content of policies in the implementation stage. Inconsistencies arise when new tools in implementation provide both incentives and disincentives for the attainment of stated policy goals (Kern and Howlett 2009; Sætren this volume). Decoupling conflict from institutional constraints in the policy formulation stage fosters policy innovation in implementation. Héritier (1999) calls this process subterfuge and uses the concept to explain why decisions are still made and implemented despite political conflict in an institutionally complex and contentious EU environment. Member states and actors in EU arenas decide, but generally national administrations implement. Encouraging the activation of different institutions and actors at different stages of the policy process across member states contains conflict and promotes experimentation, learning, and national adaptation. From an institutional perspective, ambiguity within EU policy-making both constrains and enables choice at different stages of the process.

\section{Bringing institutions back into multiple streams}

Adapting what March and Olsen (2008) have called the logic of appropriateness (the garbage can process of organizational choice) to public policy has resulted in analytical changes for MSA. Policy entrepreneurs rather than pure energy broker the process of policy-making by helping put together winning coalitions in support or opposition to proposed options. Moreover, the streams of problems and policies are not devoid of actors because they are debated, rejected, amended, and re-introduced by groups or individuals in policy communities or policy networks which are connected and affect and are affected by actors in the broader polity, such as elected officials, the media, and others. The way problems are defined and their match to policy-maker norms and biases influences where they end up on the agenda. Framing effects are not only present in the editing stage of decision, as prospect theory contends (Tversky and Kahneman 1981), but they also bias search and selection processes. All in all, MSA contends perceptions and the structure of attention produce predictable shifts in preferences and choice.

Although these changes have made the model less capricious and more familiar to students of public policy, the adaptation has come at a cost: the loss of explicit attention to organizational structure. Structural variations in garbage cans significantly affected performance. The authors of the computer simulation that underpins the garbage can model specified three decision structures that linked decision-makers to choice opportunities: open, hierarchical, and specialized. An open structure connects any decision-maker to any opportunity. The hierarchical structure links some (important) decision-makers to many choices, while less important decision-makers are connected to fewer choices. In a specialized structure, decision-makers specialize in the opportunities they may attend. The effects of non-open structure in combination with other features of the model, such as 
variations in energy load and level of problem difficulty, tend to produce long queues of important problems, lengthy decision times (the time it takes to solve problems), and high problem activity (time spent on problems activated but not addressed).

The implications of these findings were not transposed onto multiple streams (Sætren 2016). Kingdon (1984) included structural features within each stream-for example, technical feasibility increases the chances of a solution bubbling up in the policy stream or the receptivity of an idea in the political stream is partly dependent on the national mood. This argument was further refined by Zahariadis (2003, chapter 4) where the degree of structural integration in a given policy community or network was hypothesized to affect the trajectory (content and emergent speed) of solutions. But with one exception (Zohlnhöfer et al. 2015), the effects of institutions have not been systematically incorporated in the process itself. For example, does MSA have the same explanatory power in institutionally malleable, e.g., EU, or stable, e.g., Czech or Norwegian, settings? Does hierarchy affect the ability of policy entrepreneurs to forge winning coalitions?

So far, MSA has tried to model institutions in three ways: through institutional ambiguity, arenas, and duration of policy windows. The theoretical enterprise resembles what may be an unsystematic policy bricolage, the crafting of new processes by recombining a precariously maintained mix of substantive goals and symbolic elements in a given institutional repertoire that differ from but also resemble old policy expectations and outcomes. ${ }^{1}$ Such bricolage connects actors and institutions in a dual sense. To use Cairney's (2013) terms, it is synthetic by redeploying familiar elements from other theories, but also contradictory in that it adds insight and explanatory power of its own. But it is also unsystematic because the studies neither build on similar institutional designs nor do they "talk to" each other.

Ackrill and Kay (2011) infuse MSA with the concept of institutional ambiguity as a facilitator of spillovers. In the original MSA application to the USA, Kingdon (1984) observed that major policy change in one area might lead to changes in other related areas. He termed this process spillover, and hypothesized spillovers occur when policy entrepreneurs succeed in transferring winning coalitions across issue areas. In other words, success in one area opens a policy window in another. Ackrill and Kay (2011) formalize the concept by arguing there is frequently overlap across institutional boundaries, especially in the EU. In that case of jurisdictional overlap, that is, when two or more agencies deal with the same issue, one finds two types of spillovers: exogenous and endogenous. Exogenous spillovers are the ones theorized by Kingdon and depend on entrepreneurial skills to generate success across policy sectors. In contrast, endogenous spillovers are the direct outcomes of success by one agency that create a precedent and may affect outcomes in an institutionally connected but different agency. For example, the loss of the sugar case in the WTO privileged the EU's Trade Directorate-General (DG) in matters of liberalization and provided the impetus to reform sugar subsidies in 2005 , which were under the purview of the DG Agriculture. Endogenous spillover effects may be so strong even to the point of "forcing a decision when none otherwise would be made" (Ackrill and Kay 2011, 73).

Other scholars conceptualize institutions as arenas. By defining the context within which policies are made, institutions specify the types of actors that may participate, the size of the winning coalitions, and the policy alternatives that are institutionally permissible (Béland 2005). Using this schema, Ness and Misretta (2009) introduce the "policy

1 The term bricolage is often used by institutionalists to explain institutional change through recombination and reinterpretation (e.g., Campbell 2004; Cartensen 2015; Mahoney and Thelen 2010). 
milieu" as an additional element to the MSA in their examination of the use of lottery proceeds to fund education in North Carolina and Tennessee. The milieu refers to organizational structures in (USA) state governments, such as the governor's formal powers and what they term legislative professionalism. Blankenau (2001) adds to this argument the link between institutional milieu and policy windows. He maintains that greater numbers of veto points necessitate a longer policy window in order to adopt a particular policy in light of the number and magnitude of compromises that need to be made.

Reaching back to capture the decision and access structures elaborated in the original garbage can model, Zahariadis (2015) explores the effects of policy window duration on political conflict, democratic participation, and the size of policy changes. He differentiates between two links between windows and institutions: recurrent and episodic deadlines. The former are embedded in the temporal repertoire of institutions, such as national elections or budget negotiations, and the latter are externally or internally imposed by say, judges or natural catastrophes. Focusing on episodic deadlines, Zahariadis (2015) examines the implications of institutionally decelerating or accelerating the policy process. He hypothesizes inter alia the imposition of shorter windows generally reduces the likelihood of conflict by limiting participation and raising the intensity of framing effects. However, internally imposed deadlines-i.e., endogenously opened windows-increase the likelihood of conflict because they are more politically malleable, while externally imposed ones-i.e., exogenously opened windows-favor larger deviations from the status quo because policy-makers can use them to avoid blame.

The most elaborate attempt to incorporate institutions into MSA has been done by Zohlnhöfer et al. (2015). They conceptualize two nested processes, one for agenda setting (agenda coupling) and the other for decision-making (decision coupling). Formal institutions play a larger role in decision-making, and the authors proceed to specify how. They claim "while the policy and problem streams remain relevant during decision making, it is the political stream that is of prime importance during decision coupling because the main question at this point becomes: will the policy entrepreneur(s) gain the majority needed to get their pet project adopted" (p. 7)? If one accepts this proposition, it is easy to see how formal institutions shape the majority and rules by which compromises are attempted and winning coalitions built. Political parties play a big role in shaping a receptive audience to problem-solution packages. For example, in Westminster-type majoritarian democracies, a proposal backed by the majority party will likely be adopted quickly and with little compromise. However, in light of a bicameral legislature or a presidential system with a distinct separation of powers, a condition they term institutional pluralism, parties in general play a lesser role and entrepreneurs become more important in brokering support.

\section{The way forward}

The special issue picks up where the literature on MSA has left off. The authors revisit institutional ambiguity, arenas, and window duration and add one more novel element: the structural element of coupling, i.e., policy entrepreneurship. This is the first systematic attempt by scholars to "talk to" one another and build on previous MSA literature by confirming and refining hypotheses regarding institutional effects. The two articles by Herweg and Saurugger and Terpan explore how institutional perturbations in entrepreneurship and temporal context affect policy change. Rozbicka and Spohr analytically specify the strategies of interest groups in well-defined institutional milieu, while 
Sætren explores the effects of entrepreneurial strategy and institutional position on coupling success. Novotný and Polášek articulate the logic of endogeneity in reforming political organizations. Using the MSA, the first two explore the effects of institutions on the policy process, while the latter three examine how actors and strategies affect institutions.

Herweg applies MSA to explain the EU agenda regarding gas directives. She first explains the difference between national and EU political streams. Because the institutional morphology differs significantly at the EU level, it is important to specify what the EU political stream is. Operating under institutional pluralism, she makes some important changes. First, she drops the European mood from the equation and elevates the position of the Commission. Second, the European Council plays a role in opening policy windows per statutory powers in addition to the President of the Consilium. National rather than partisan affiliation makes the difference. Finally, due to the extreme heterogeneity of actors in the EU policy stream, technical feasibility is the only criterion of an idea's survival. Despite dramatic institutional adaptations, the author still affirms the basic MSA logic: Items rise on the agenda when streams are ripe, policy windows open, and entrepreneurs actively couple the three streams.

Saurugger and Terpan examine the conditions that promote hardening or softening of norms during periods of economic crisis. Focusing on EU economic governance during two time periods in the 2000s, they provide empirical support for the claim that wider policy windows (and by implication a longer policy process) are more likely to lead to legally constraining norms [in the sense of large deviations from the status quo that Zahariadis (2015) hypothesizes]. Like Herweg, they, too, adapt the politics stream away from partisan affiliations to an examination of support or opposition on a national basis. The originality and institutional innovation the authors propose revolves around the importance of a crucial variable unique at the EU level: degree of consensus-based coherence among policy entrepreneurs. It is the heterogeneity of EU interests and institutional fluidity that elevate the significance of coherence. Structural features of windows similarly affect the size of policy change: Wider windows lead to more far-reaching policy change. But the authors acknowledge the need to embed actors in institutions. Policy entrepreneurs, who coalesce around a coherent message, in hierarchically placed agencies are more likely to be successful in getting their pet proposal adopted.

Rozbicka and Spohr address the importance of interest groups in multi-governance settings. Drawing on evidence from national welfare regimes in pluralist and corporatist settings and juxtaposing it against the EU background, they explore the effects of resources, feedback, and public appeal on access to the policy process. They find inter alia that institutionally integrated corporatist systems inhibit access to new entrants by formalizing participation and ensuring stability. As systems become less integrated, i.e., more pluralist, the likelihood of access increases and so do the chances of unstable winning coalitions and policy reversals. More importantly, like Saurugger and Terpan they contend the entrepreneurial power of coherent interest groups is enhanced at the EU level because of the latter's malleable institutions and absence of centralized authority. In other words, different institutional configurations privilege different actors, but they do not affect MSA's temporal order and coupling logic.

Sætren examines the improbable success of a skilled entrepreneur in helping to decentralize (relocate) Norwegian central government agencies to various provinces. Looking at three instances of intent to relocate, he finds only one succeeded and that against all odds. The entrepreneur (minister) was a party outsider who faced insurmountable odds against an organized and determined opposition. Two factors inter alia 
made it possible to succeed: institutional position and manipulative design. The entrepreneur audaciously defied his own party and the established policy tool of launching a public investigative expert commission prior to proposing a policy. Instead, he used his position to create a tightly and politically steered intra-ministerial project group to craft a regionally balanced deal that could satisfy diverse interests in parliament. Interestingly, Sætren revisits the hypothesis posed by Zohlnhöfer et al. (2015) and finds that even in the less institutionally pluralist environment of Norway, policy entrepreneurs rather than political parties make a difference.

Novotný and Polášek broaden MSA's scope of applicability by examining the modernization process of the Czech Social Democratic party. They find that the size of policy windows affected the size and scope of outcome (modernization) in an endogenous trajectory: Narrow reforms brought electoral success and new dynamism to the party. Ironically, it was electoral defeat that opened a wider window for broader reform to reorganize the political base, add new objectives and rules, and strengthen the leadership's control. Nevertheless, it was institutional ambiguity in the form of overlap, the conflation of partisan and executive/official roles, which prompted problem overload and ultimately closed the window for reform. By linking incomplete and uneven implementation to policy windows, the authors get back to the argument by Blankenau (2001) through a different mechanism: The size of reforms (and by implication the number of potential veto players) at time $t$ affects the duration of the policy window at time $t+1$.

All in all, the articles in this special issue revisit and expand on some of the institutional innovations attempted in earlier MSA studies. The authors refine hypotheses regarding the role of institutions in MSA, such as the relationship between duration of windows and scope of policies and the unique institutional configuration at the EU level. They also empirically confirm others, such as the ripeness of streams, entrepreneurial strategies, and the role of institutions in privileging entrepreneurial coupling.

To return back to Pythia, the policy process resembles in many ways the ritualistic process of a Delphic oracle. While the ambiguity inherent in the content serves multiple objectives, the process is interactively shaped by prevailing institutional morphology. Institutions shape and constrain content and process. They play the role of Delphic useful deceivers. The articles help paint an incomplete picture by which we can partially understand the mechanisms of how this is done. But more research is needed to replicate and further refine the arguments advanced in an effort to more clearly understand how ambiguity adds meaning and purpose to public policy.

\section{References}

Ackrill, R., \& Kay, A. (2011). Multiple streams in EU policy-making: The case of the 2005 sugar reform. Journal of European Public Policy, 18(1), 72-89.

Béland, D. (2005). Ideas and social policy: An institutionalist perspective. Social Policy \& Administration, $39(1), 1-18$.

Birkland, T. A. (2004). 'The world changed today': Agenda-setting and policy change in the wake of the September 11 terrorist Attacks. Review of Policy Research, 21(2), 179-200.

Blankenau, J. (2001). The fate of national health insurance in Canada and the United States: A multiple streams explanation. Policy Studies Journal, 29(1), 38-55.

Cairney, P. (2013). Standing on the shoulders of giants: How do we combine the insights of multiple theories in public policy studies? Policy Studies Journal, 41(1), 1-21.

Campbell, J. L. (2004). Institutional change and globalization. Princeton, NJ: Princeton University Press. 
Cartensen, M. B. (2015). Institutional bricolage in times of crisis. European Political Science Review. doi: $10.1017 /$ S1755773915000338.

Cohen, M. D., March, J. G., \& Olsen, J. P. (1972). A garbage can model of organizational choice. Administrative Science Quarterly, 17(1), 1-25.

Hajer, M. A. (2003). Policy without polity? Policy analysis and the institutional void. Policy Sciences, 36, $175-195$.

Héritier, A. (1999). Policy-making and diversity in Europe: Escape from deadlock. Cambridge, UK: Cambridge University Press.

Jones, B. D., \& Baumgartner, F. R. (2005). The politics of attention: How government prioritizes problems. Chicago: University of Chicago Press.

Jones, M. D., Peterson, H. L., Pierce, J. J., Herweg, N., Bernal, A., Raney, H. L., \& Zahariadis, N. (2016). A river runs through it: A multiple streams meta-review. Policy Studies Journal, 44(1), 13-36.

Kern, F., \& Howlett, M. (2009). Implementing transition management as policy reforms: A case study of the Dutch energy sector. Policy Sciences, 42(4), 391-408.

Kingdon, J. (1984). Agendas, alternatives, and public policies. Boston: Little, Brown.

Mahoney, J., \& Thelen, K. (Eds.). (2010). Explaining institutional change: Ambiguity, agency, and power. Cambridge: Cambridge University Press.

March, J. G. (1991). How decisions happen in organizations. Human-Computer Interaction, 6, 95-117.

March, J. G., \& Olsen, J. P. (1989). Rediscovering institutions: The organizational basis of politics. New York: Free Press.

March, J. G., \& Olsen, J. P. (2008). The logic of appropriateness. In R. E. Goodin, M. Moran, \& M. Rein (Eds.), The Oxford handbook of public policy. Oxford: Oxford University Press.

March, J. G., \& Romelaer, P. (1976). Position and presence in the drift of decisions. In J. G. March \& J. P. Olsen (Eds.), Ambiguity and choice in organizations. Bergen: Univesitetsforlaget.

Ness, E. C., \& Misretta, M. A. (2009). Policy adoption in North Carolina and Tennessee: A comparative case study of lottery beneficiaries. Review of Higher Education, 32(4), 489-514.

North, D. C. (1990). Institutions, institutional change and economic performance. Cambridge: Cambridge University Press.

Orton, J. D., \& Weick, K. E. (1990). Loosely coupled systems: A reconceptualization. Academy of Management Review, 15(2), 203-223.

Peters, B. G. (2012). Institutional theory in political science: The new institutionalism (3rd ed.). New York: Continuum.

Ridde, V. (2009). Policy implementation in an African state: An extension of Kingdon's multiple streams approach. Public Administration, 87(4), 938-954.

Risse, T. (2010). A community of Europeans?. Ithaca, NY: Cornell University Press.

Sætren, H. (2016). Lost in translation: Re-conceptualizing the multiple streams framework back to its source of inspiration. In R. Zohlnhöfer \& F. Rüb (Eds.), Decision-making under ambiguity and time constraints: Assessing the multiple streams framework. Colchester: ECPR Press.

Schattschneider, E. E. (1960). The semi-sovereign people. New York: Holt, Reinhart and Winston.

Schlager, E. (2007). A comparison of frameworks, theories, and models of policy processes. In P. A. Sabatier (Ed.), Theories of the policy process ( 2 nd ed.). Boulder, CO: Westview Press.

Tversky, A., \& Kahneman, D. (1981). The framing of decisions and the psychology of choice. Science, 211(4481), 453-458.

Weber, K., \& Glynn, M. A. (2006). Making sense with institutions: Context, thought and action in Karl Weick's theory. Organization Studies, 27(11), 1639-1660.

Weick, K. E. (1995). Sensemaking in organizations. Thousand Oaks, CA: Sage.

Zahariadis, N. (1995). Markets, states and public policy. Ann Arbor: University of Michigan Press.

Zahariadis, N. (2003). Ambiguity and choice in public policy. Washington, DC: Georgetown University Press.

Zahariadis, N. (2014). Ambiguity and multiple streams. In P. A. Sabatier \& C. M. Weible (Eds.), Theories of the policy process (3rd ed.). Boulder, CO: Westview Press.

Zahariadis, N. (2015). Plato's receptacle: Deadlines, ambiguity, and temporal sorting in public policy. Leviathan, 30, 113-131.

Zohlnhöfer, R., Herweg, N., \& Huß, C. (2015). Bringing formal political institutions into the multiple streams framework: An analytical proposal for comparative policy analysis. Journal of Comparative Policy Analysis. doi:10.1080/13876988.2015.1095428. 